\title{
A EXPANSÃO DA MONOCULTURA CANAVIEIRA NO MUNICÍPIO DE OURO VERDE - SP
}

\section{Leandro Reginaldo Maximino Lelis ${ }^{1}$}

\author{
Francisco José Avelino Júnior ${ }^{2}$
}

\begin{abstract}
RESUMO
O processo de modernização da agricultura foi incentivado pelo Estado e viabilizou a expansão das atividades agrícolas desenvolvidas em grande escala no Brasil, como é o caso da monocultura da cana-de-açúcar. Destarte, este artigo tem como objetivo analisar os impactos gerados pela expansão da cana-de-açúcar no município de Ouro Verde. A partir da leitura do material bibliográfico selecionado e da análise dos dados de fontes secundárias, constatamos que a expansão da lavoura canavieira gerou impactos socioambientais significativos no município analisado.
\end{abstract}

PALAVRAS-CHAVE: Modernização da agricultura. Cana-de-açúcar. Impactos socioambientais.

\section{THE EXPANSION OF SUGARCANE MONOCULTURE IN THE MUNICIPALITY OF OURO VERDE - SP}

\begin{abstract}
The process of agricultural modernization was encouraged by the State and made viable the expansion of farming activities developed on a large scale in Brazil, as is the case the sugarcane monoculture. Thus, this article aims to analyze the impacts generated by the expansion of sugarcane in the municipality of Ouro Verde. From the reading of the selected bibliographic material and analysis of data from secondary sources, we verified that the expansion of sugarcane tillage generated significant social and environmental impacts in the municipality analyzed.
\end{abstract}

KEYWORDS: Modernization of agriculture. Sugarcane. Social and environmental impacts.

\section{LA EXPANSIÓN DE MONOCULTIVO DE CAÑA DE AZÚCAR EN EL MUNICIPIO DE OURO VERDE - SP}

\footnotetext{
${ }^{1}$ Mestrando no Programa de Pós-Graduação em Geografia da Universidade Federal de Mato Grosso do Sul, campus de Três Lagoas. E-mail: sukko51@hotmail.com

2 Docente do Programa de Pós-Graduação em Geografia da Universidade Federal de Mato Grosso do Sul, campus de Três Lagoas. E-mail: chinaufms@hotmail.com
} 


\section{RESUMEN}

El proceso de modernización de la agricultura fue alentado por el Estado e viabilizó la expansión de las actividades agrícolas a gran escala en Brasil, como es el caso de monocultivo de la caña de azúcar. Así, este artículo tiene como objetivo analizar los impactos generados por la expansión de la caña de azúcar en el municipio de Ouro Verde. A partir de la lectura del material bibliografico selecionado y de análisis de datos de fuentes secundarias, constatamos que la expansión de labranza de caña de azúcar generó impactos sociales y ambientales en el municipio analizado.

PALABRAS CLAVE: Modernización de la agricultura. Caña de azúcar. Los impactos sociales y ambientales.

\section{INTRODUÇÃO}

Até a década de 1950, a agricultura era considerada o setor tradicional da economia que prejudicava o desenvolvimento industrial no Brasil. Durante a década de 1950 esse pensamento foi alterado e a agricultura passou a ser vista como uma forma de inserção do Brasil na economia internacional. Todavia, para que isso ocorresse, seria necessário aumentar a produção e a produtividade agrícola. A forma escolhida pelo Estado brasileiro para alcançar esse intento foi estimular a modernização da agricultura (ANDRADE, 1979).

Dessa maneira, a partir da década de 1950, o Estado passou a disseminar a ideia que a modernização das atividades agrícolas era necessária e seria realizada para proporcionar o desenvolvimento do país (ANDRADE, 1979). Vale salientar que o processo de modernização da agricultura foi essencial para viabilizar a expansão das atividades agrícolas praticadas em grande escala no Brasil, como é o caso da monocultura da cana-de-açúcar.

No município de Ouro Verde, a monocultura canavieira se expandiu no início da década de 2000 e provocou desdobramentos socioambientais significativos na localidade pesquisada. Neste contexto, este trabalho tem como objetivo analisar os impactos gerados pelo processo de expansão da cana-de-açúcar no município de Ouro Verde. Para a consecução do objetivo proposto, realizamos os seguintes procedimentos metodológicos: pesquisa bibliográfica e leitura do material selecionado; e, coleta e sistematização de dados de fontes secundárias. A pesquisa bibliográfica foi realizada sobre os seguintes temas: territorialização do capital no campo; modernização da agricultura brasileira; e, expansão da cana-de-açúcar no oeste do Estado de São Paulo. Os dados de fontes secundárias foram obtidos no site do Instituto Brasileiro de Geografia e Estatística (IBGE), através dos acervos 
eletrônicos da Pesquisa Pecuária Municipal e da Produção Agrícola Municipal. O recorte temporal delineado para obtenção e análise dos dados de fontes secundárias compreendeu o período entre os anos de 2000 e 2013.

\section{A MODERNIZAÇÃO DA AGRICULTURA BRASILEIRA}

Durante décadas, a agricultura foi considerada pelo Estado brasileiro o setor tradicional da economia que prejudicava o desenvolvimento industrial no Brasil. Isso ocorria em função de sua incapacidade de fornecer a quantidade necessária de matéria-prima para as fábricas, bem como, pelo pequeno poder de compra dos trabalhadores agrícolas, impossibilitando o consumo de produtos industrializados (ANDRADE, 1979).

De acordo com Matos e Pessôa (2011), na visão do Governo Federal brasileiro, o campo brasileiro estava "atrasado" naquele momento. Assim, para o Estado, as atividades agrícolas eram realizadas de forma arcaica. Além disso, somava-se a pouca expressão econômica das culturas destinadas ao mercado internacional naquele período.

No decorrer da década de 1950, esse pensamento foi alterado e a agricultura passou a ser vista como uma possibilidade de inserção do Brasil na economia internacional. Entretanto, para que isso ocorresse, seria necessário aumentar a produção e a produtividade agrícola. A estratégia escolhida pelo Estado brasileiro para alcançar esse objetivo foi a modernização das atividades agrícolas. Desse modo, a partir da década de 1950, o Estado propagou a ideia de que a modernização da agricultura era necessária para o desenvolvimento econômico do país. No entanto, foi somente a partir da década de 1960 que a modernização da agricultura começou a se consolidar no campo brasileiro (ANDRADE, 1979).

Para Oliveira (1996), a dívida externa foi o principal motivo para que ocorresse o aumento da produção destinada ao mercado externo. Isso porque, para quitar suas dívidas, o governo brasileiro tinha que exportar produtos agropecuários. O Brasil teve que ampliar a produção para conseguir continuar pagando suas dívidas, já que os preços das matérias-primas que o Brasil exportava naquele período estavam em baixa. 
O Governo Federal exerceu papel fundamental para viabilizar a consolidação da modernização da agricultura no Brasil. Através dos órgãos governamentais realizou uma série de investimentos financeiros que possibilitaram essa modernização. A grande questão foi a desigualdade existente na destinação desses investimentos. Enquanto os grandes produtores rurais usufruíram de uma série de vantagens e facilidades, os pequenos produtores sofreram com a falta de apoio e incentivo governamental, ficando, dessa forma, marginalizados perante à essa série de investimentos estatais no campo brasileiro (ANDRADE, 1979).

Desta maneira, a expansão do modo de produção capitalista no campo brasileiro só foi possível graças ao apoio governamental. Este apoio se deu através de facilidades de financiamento às grandes propriedades, subsídios financeiros, isenção de impostos, entre outros benefícios (GRAZIANO DA SILVA, 1982).

Devido aos grandes investimentos realizados pelo Estado, diversos autores apontam que a modernização da agricultura foi consolidada e prospera atualmente em decorrência do apoio irrestrito do Estado (MATOS; PESSÔA, 2011).

Ressaltando o papel do Estado no setor agrícola, Martins (1975) afirma que a política econômica estatal regula o setor externo e o setor interno. Destarte, os produtos agrícolas destinados ao mercado externo e interno são regulados pelo Estado, "[...] seja porque deles depende substancialmente a receita cambial do país, empregada na industrialização, seja porque passaram a ter consumo expressivo ou preponderante no mercado interno" (MARTINS, 1975, p. 59).

Kudlavicz (2011) aponta que a modernização da agricultura no Brasil foi possível em função de um planejamento bem articulado entre o poder público e o privado. Além disso, o autor supracitado avalia que as instituições de pesquisa foram essenciais para a consolidação do processo de modernização das atividades agropecuárias desenvolvidas no Brasil.

Nesse sentido, Matos e Pessôa (2011) apontam que a criação da Empresa Brasileira de Pesquisa Agropecuária (EMBRAPA), em 1971, foi fundamental para viabilizar a expansão da agricultura moderna. As pesquisas científicas desenvolvidas pela EMBRAPA passaram a ser realizadas "[...] para o melhoramento da produção, na tentativa de corrigir as deficiências dos solos, prevenir doenças, aumentar o rendimento por hectares, atender as exigências do mercado quanto a variedade produzida, tamanho, sabor etc. [...]" (MATOS; PESSÔA, 2011, p. 303). 
Os meios de comunicação também exerceram papel fundamental para a consolidação do processo de modernização da agricultura, já que foram utilizados para disseminar a ideia de que a modernização agrícola e o consequente aumento da produção e da produtividade seriam realizados para beneficiar a população. Assim, os meios de comunicação difundiram a ideia que os danos sociais e ambientais eram prejuízos necessários para que ocorresse o desenvolvimento e 0 progresso do Brasil (ANDRADE, 1979). Nesse contexto, Almeida (2012) corrobora:

[...] o desenvolvimento econômico é um mito cuja funcionalidade é criar um imaginário coletivo centrado na ideia de que todos serão beneficiados pelo desenvolvimento do capital, situação que leva os povos a aceitar sacrifícios que incluem formas de dependência e de destruição do meio físico (ALMEIDA, 2012, p. 12).

A respeito da modernização da agricultura, Matos e Pessoa (2009) afirmam que esse processo proporcionou muito mais desvantagens do que vantagens. Como vantagens as autoras citam o aumento da produção e da produtividade agropecuária que ocorreram em função das inovações tecnológicas. Já do ponto de vista negativo, apontam que esse processo contribuiu para aumentar a concentração fundiária e de renda, além de ampliar as desigualdades regionais e expulsar milhares de famílias do campo.

As inovações tecnológicas que proporcionam o aumento da produção e da produtividade agropecuária também possuem grande responsabilidade na expulsão de milhares de famílias no campo. Tal situação ocorre porque o trabalho humano é cada vez mais substituído pelas máquinas.

Para Oliveira (2003), a modernização do campo brasileiro tem transformado a agricultura em uma atividade que é pautada no lucro e regulada pelo mercado internacional. Nesse sentido, Oliveira (2003) corrobora que o campo brasileiro está cada vez mais submetido ao mercado internacional e à lógica contraditória da mundialização do capital.

Neste contexto, Graziano da Silva (1982) aponta que o que se vê no campo brasileiro é uma modernização conservadora e dolorosa. Conservadora porque privilegia somente algumas culturas (principalmente as destinadas ao mercado externo) e regiões, bem como, somente alguns tipos de unidades produtivas (médias e grandes propriedades rurais). Dolorosa porque gerou graves contradições sociais 
em decorrência da expansão da lógica capitalista. Assim, o processo de modernização do campo brasileiro nunca possuiu um caráter dinâmico e homogêneo, pelo contrário, essa modernização induzida implicou em "[...] pesados custos sociais e que só vinga pelo amparo do Estado" (GRAZIANO DA SILVA, 1982, p. 40).

O processo de modernização das atividades agrícolas provocou alterações significativas na dinâmica social, econômica e ambiental do campo brasileiro. Além disso, esse processo foi fundamental para viabilizar a expansão das atividades agrícolas praticadas em grande escala no Brasil, como é o caso da monocultura canavieira.

\section{A EXPANSÃO DA MONOCULTURA CANAVIEIRA EM OURO VERDE}

A fundação de Ouro Verde ocorreu em 1945, em decorrência da expansão da atividade cafeeira para o Oeste do Estado de São Paulo em um movimento expansionista que ficou conhecido como "Marcha para o Oeste" (MONBEIG, 1984). O café, inclusive, originou o nome do município. Em virtude da riqueza gerada pela atividade cafeeira naquele período, o café era considerado um verdadeiro "ouro verde". Além do café, a venda de lotes pelas empresas colonizadoras também foi fundamental para o início da formação de Ouro Verde, que está localizado na Microrregião de Dracena (Figura 1) (GIL, 2007). 
Figura 1. Localização de Ouro Verde na Microrregião de Dracena.

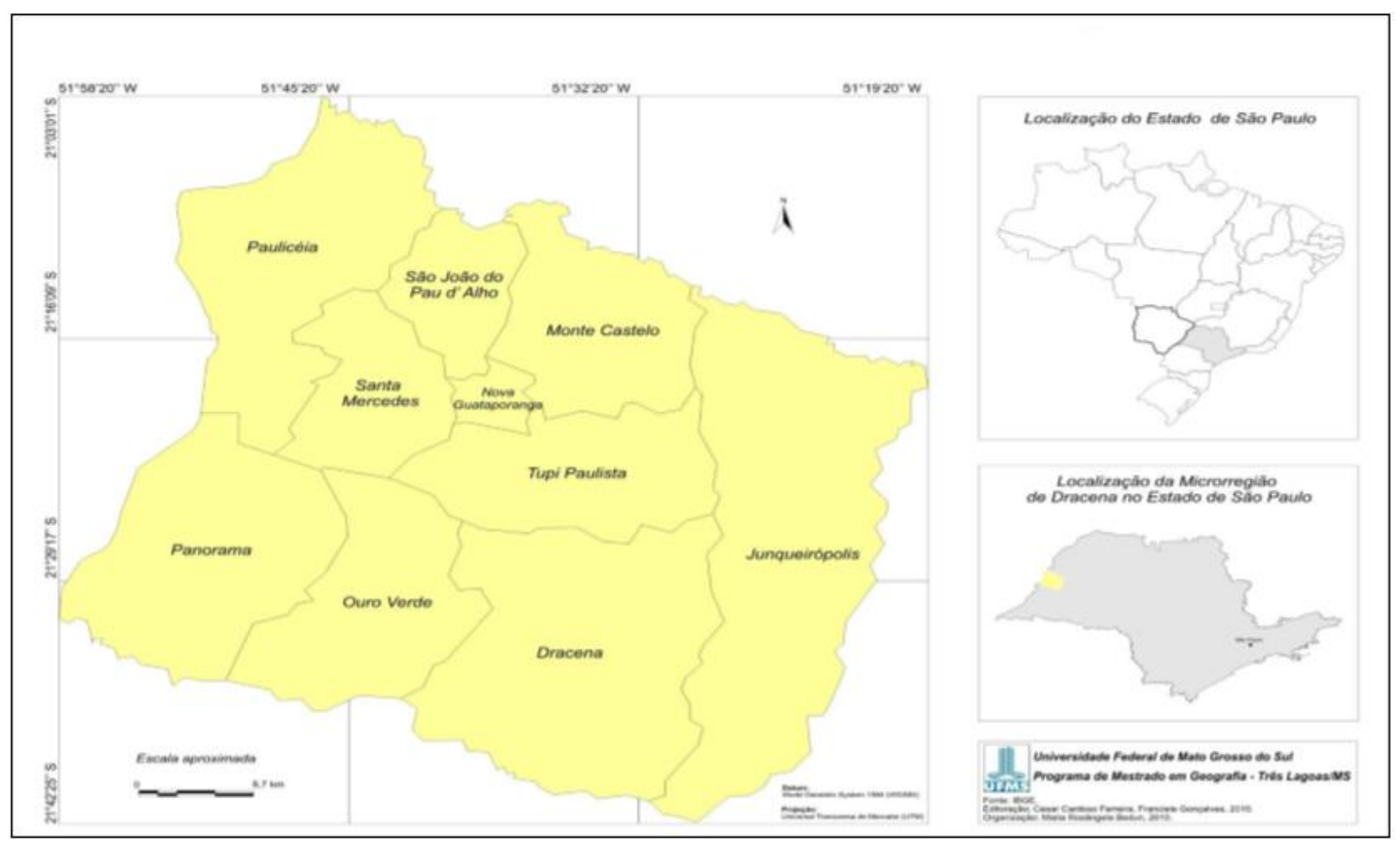

Fonte: BEDUN, 2012.

Entre as décadas de 1940 e 1980, a cultura cafeeira foi a principal atividade econômica de Ouro Verde. Durante esse período, o café proporcionou seu crescimento econômico. No entanto, na década de 1980, essa situação alterou-se. Nesta década, a crise do café gerou profunda estagnação econômica, que perdurou entre as décadas de 1980 e 1990. A partir do início da década de 2000, a lavoura canavieira se expandiu em Ouro Verde e proporcionou relativo resgate da economia local (LELIS; HESPANHOL, 2013).

A instalação de usinas sucroalcooleiras em municípios da Microrregião de Dracena fez com que os canaviais se expandissem em Ouro Verde. No início da década de 2000, houve a reativação da Destilaria Vale Verde, em Junqueirópolis, que havia sido fechada em 1998. A partir de sua reativação, a destilaria passou a se chamar Usina Alta Paulista. No ano de 2006, três usinas sucroalcooleiras foram inauguradas na microrregião: Usina Dracena Álcool e Açúcar Ltda, em Dracena; Usina Rio Vermelho Álcool e Açúcar Ltda, em Junqueirópolis; e, Destilaria Caiuá S/A, em Santa Mercedes. Em 2009, foi inaugurada a Usina Caeté S/A, no município de Paulicéia. 
De acordo com Joviano (2009), vários fatores internos e externos contribuíram para impulsionar a expansão da monocultura canavieira no início da década de 2000, tais como:

[...] oscilações e aumento dos preços do petróleo motivado por um ambiente de tensão na região do Oriente Médio; a busca por fontes energéticas renováveis; o domínio da tecnologia para produção do álcool e aproveitamento de subprodutos da produção como o bagaço na energia e o vinhoto para fertilização por irrigação; o crescimento na demanda de álcool motivada pela produção de veículos bicombustível e do aumento de consumo de açúcar e álcool em países como China e Índia; questões ambientais que colocam a necessidade de substituição de derivados de petróleo para evitar as emissões de $\mathrm{CO}^{2}$, dentre outros (JOVIANO, 2009, p. 140).

No município de Ouro Verde, alguns fatores foram fundamentais para atrair o interesse dos empresários do setor sucroalcooleiro, dentre os quais destacamos os fatores agronômicos, econômicos, sociais e políticos (SEGATTI, 2009).

Do ponto de vista dos fatores agronômicos, "[...] destacam-se os solos podzolizados e areníticos, que, apesar da fertilidade mediana, oferecem boas respostas às adubações" (SEGATTI, 2009, p. 65). Além disso, o relevo suavemente ondulado do município, favorece o corte mecanizado.

No que diz respeito aos fatores econômicos, podemos apontar o baixo custo da mão de obra e o baixo preço das terras da região, seja para arrendar ou para comprar (SEGATTI, 2009; LELIS; HESPANHOL, 2013).

Quanto aos fatores sociais, a idade média avançada dos agricultores é um dos principais fatores que proporcionam a expansão da monocultura canavieira, haja vista que tal expansão não encontra resistência por parte dos agricultores (SEGATTI, 2009).

Somado a todos esses fatores, existe um fator ainda mais incisivo: a incipiente e quase inexistente política sindical local. Para alguns esse é o principal fator que fez com que a expansão da cana-de-açúcar ocorra de maneira desenfreada, tendo em vista que as organizações sindicais se configuram como empecilhos para o setor em outras regiões (SEGATTI, 2009).

A expansão dos canaviais pode ser mensurada através da análise dos dados referentes à área ocupada pela cana-de-açúcar no município de Ouro Verde. Como pode ser constatado na Tabela 1, a área plantada com a cana-de-açúcar cresceu 
significativamente durante o período analisado. No ano de 2000, não houve registro de área plantada com cana-de-açúcar em Ouro Verde. Em 2005, a área plantada de cana-de-açúcar foi de 2.205 hectares. Já em 2013, a área destinada ao cultivo de cana-de-açúcar passou a ocupar 10.340 hectares na localidade pesquisada, configurando aumento de $468,9 \%$.

Tabela 1. Área plantada de cana-de-açúcar em Ouro Verde.

\begin{tabular}{lcccc}
\hline Tipo de Lavoura & $\mathbf{2 0 0 0}$ & $\mathbf{2 0 0 5}$ & $\mathbf{2 0 1 0}$ & $\mathbf{2 0 1 3}$ \\
\cline { 2 - 5 } & Hectares & Hectares & Hectares & Hectares \\
Cana-de-açúcar & - & 2.205 & 9.710 & 10.340 \\
\hline
\end{tabular}

Fonte: Produção Agrícola Municipal do IBGE (2000 - 2013).

O crescimento da produção de cana-de-açúcar (Tabela 2) durante o período analisado também é uma evidência da expansão da monocultura canavieira em Ouro Verde. Em 2000, não houve registro de produção de cana-de-açúcar. No ano de 2005, a produção foi de 186.168 toneladas. Enquanto isso, em 2013, a produção saltou para 800.000 toneladas, evidenciando acréscimo de $429,7 \%$.

Tabela 2. Produção de cana-de-açúcar em Ouro Verde.

\begin{tabular}{lcccc}
\hline Tipo de Lavoura & $\mathbf{2 0 0 0}$ & $\mathbf{2 0 0 5}$ & $\mathbf{2 0 1 0}$ & $\mathbf{2 0 1 3}$ \\
\cline { 2 - 5 } & Toneladas & Toneladas & Toneladas & Toneladas \\
Cana-de-açúcar & - & 186.168 & 776.800 & 800.000 \\
\hline
\end{tabular}

Fonte: Produção Agrícola Municipal do IBGE (2000 - 2013).

O valor da produção é outro indício da expansão da monocultura canavieira em Ouro Verde, conforme podemos constatar na Tabela 3. Entre os anos 2005 e 2013, o valor gerado pela produção de cana-de-açúcar em Ouro Verde cresceu $857,1 \%$. Enquanto em 2000 o valor total da produção foi de pouco mais de 5 milhões de reais, em 2012 o valor gerado aumentou para mais de 44 milhões de reais. 
Tabela 3. Valor gerado pela produção de cana-de-açúcar em Ouro Verde.

\begin{tabular}{lcccc}
\hline Tipo de lavoura & $\mathbf{2 0 0 0}$ & $\mathbf{2 0 0 5}$ & $\mathbf{2 0 1 0}$ & $\mathbf{2 0 1 3}$ \\
\cline { 2 - 5 } & (Mil reais) & (Mil reais) & (Mil reais) & (Mil reais) \\
Cana-de-açúcar & - & 5.213 & 32.625 & 44.680 \\
\hline
\end{tabular}

Fonte: Produção Agrícola Municipal do IBGE (2000 - 2013).

A expansão da monocultura canavieira tem provocado intensa reestruturação espacial, produtiva e econômica no município de Ouro Verde. Nesse contexto, o próximo item tem como objetivo analisar os impactos socioambientais gerados por essa expansão na localidade pesquisada.

\section{OS IMPACTOS GERADOS PELA EXPANSÃO DA CANA-DE-AÇÚCAR EM OURO VERDE}

A expansão da monocultura canavieira proporcionou inúmeras desvantagens para o município de Ouro Verde, tendo em conta que essa expansão gerou impactos socioambientais extremamente significativos.

Do ponto de vista social, a expansão da lavoura canavieira proporcionou impactos devido à sazonalidade da maioria dos empregos gerados por esse setor econômico, desarticulou as comunidades rurais, aumentou a concentração de renda e de terra no campo e dificultou o desenvolvimento das atividades agropecuárias praticadas em pequena escala (SEGATTI, 2009; LELIS; HESPANHOL, 2013).

No que se refere aos danos ambientais, a alteração na paisagem em decorrência de sua homogeneização, a diminuição da biodiversidade e as queimadas $^{3}$ figuram como alguns dos principais problemas ambientais gerados pela expansão da monocultura canavieira. Não é somente no campo que a fumaça e a fuligem das queimadas da cana-de-açúcar são facilmente notadas, já que elas também chegam à cidade. Além disso, as queimadas também provocam a morte de animais. A poluição do solo, da água e do ar em decorrência da utilização

\footnotetext{
${ }^{3}$ No Estado de São Paulo, a Lei no 11.241, de 19 de setembro 2002, controla a queima da cana-deaçúcar. Está previsto que a partir do ano de 2014 as plantações que estiverem em áreas com declividade de até $12 \%$, não poderão ser queimadas, sendo obrigatória a colheita mecanizada da cana-de-açúcar crua. Nas demais áreas, o prazo será até o ano de 2017.
} 
demasiada de agrotóxicos e a proliferação de pragas e doenças derivadas da cultura canavieira em culturas circunvizinhas também se configuram como impactos ambientais negativos (SEGATTI, 2009; LELIS; HESPANHOL, 2013).

No campo, a expansão dos canaviais configure-se como obstáculo para os pequenos produtores rurais. A competição está cada vez mais desigual em favor da expansão da monocultura canavieira. $O$ arrendamento de pequenas e médias propriedades rurais para o cultivo da cana-de-açúcar tem favorecido a diminuição das lavouras temporárias e permanentes e dos rebanhos de animais.

A Tabela 4 apresenta os dados referentes à produção das principais lavouras temporárias do município de Ouro Verde. Essa tabela reforça a tese de que a expansão dos canaviais tem culminado na redução da produção de outros tipos de lavouras. Em 2000, a produção de algodão era de 581 toneladas, enquanto em 2013 não houve registro de produção. A lavoura de amendoim é a única que apresentou crescimento durante o período analisado, tendo em vista que sua produção passou de 965 toneladas, em 2005, para 1.250 toneladas, em 2013. As lavouras de feijão, mandioca e melância, que em anos anteriores registram produção, sequer registraram produção no ano de 2013. Além do amendoim, o milho é a única lavoura temporária que registrou produção em 2013, todavia, quando comparada com a produção registrada em 2000, notamos que a produção de milho apresentou decréscimo de $97,6 \%$.

Tabela 4. Produção das principais lavouras temporárias de Ouro Verde.

\begin{tabular}{lcccc}
\hline Tipo de lavoura & $\mathbf{2 0 0 0}$ & $\mathbf{2 0 0 5}$ & $\mathbf{2 0 1 0}$ & $\mathbf{2 0 1 3}$ \\
\cline { 2 - 5 } Algodão & Toneladas & Toneladas & Toneladas & Toneladas \\
Amendoim & 581 & 76 & - & - \\
Feijão & - & - & 965 & 1.250 \\
Mandioca & - & 300 & 54 & - \\
Melancia & 45 & 2.156 & - & - \\
Milho & 1.040 & 1.580 & - & - \\
\hline
\end{tabular}

Fonte: Produção Agrícola Municipal do IBGE (2000 - 2013). 
Assim como verificado com as lavouras temporárias, a produção das lavouras permanentes também reduziu durante o período analisado, conforme evidencia a Tabela 5. Entre os anos 2000 e 2013, o café apresentou redução de $95,4 \%$ em sua produção. A laranja e o limão, que em 2000 registraram produções significativas, sequer tiveram produções registradas a partir do ano de 2005. A manga registrou redução de $71 \%$ durante o período analisado. A redução da produção de maracujá foi de $98,3 \%$. Já a uva, apesar de registrar produção entre os anos de 2000 e 2010, não registrou produção em 2013.

Tabela 5. Produção das principais lavouras permanentes de Ouro Verde.

\begin{tabular}{lcccc}
\hline Tipo de lavoura & $\mathbf{2 0 0 0}$ & $\mathbf{2 0 0 5}$ & $\mathbf{2 0 1 0}$ & $\mathbf{2 0 1 3}$ \\
\cline { 2 - 5 } & Toneladas & Toneladas & Toneladas & Toneladas \\
Café (em grão) & 546 & 105 & 109 & 25 \\
Laranja & 5.000 & - & - & - \\
Limão & 2.640 & - & - & - \\
Manga & 2.001 & 1.716 & 1.080 & 580 \\
Maracujá & 1.550 & 225 & 30 & 26 \\
Uva & 763 & 370 & 420 & - \\
\hline
\end{tabular}

Fonte: Produção Agrícola Municipal do IBGE (2000 - 2013).

Segundo os dados do acervo eletrônico da Produção Agrícola Municipal, disponíveis no site do IBGE, todas as lavouras temporárias e permanentes, com exceção do amendoim, reduziram durante o período analisado no município de Ouro Verde.

Assim como verificado com as lavouras temporárias e permanentes, o efetivo dos rebanhos (Tabela 6) também tem apresentado redução no município pesquisado. Entre os anos de 2000 e 2013, o rebanho bovino diminuiu 42\%. Neste mesmo período, os equinos e as galináceas também tiveram seus rebanhos reduzidos em $63 \%$ e $61 \%$, respectivamente. O rebanho de ovinos foi o único que cresceu durante o período analisado, passando de 700 cabeças, em 2000, para 1.080 , em 2013, evidenciando crescimento de $35,2 \%$. Os rebanhos de suínos e equinos também reduziram entre os anos de 2000 e 2013. Enquanto o rebanho suíno reduziu $17,8 \%$, o rebanho equino reduziu $63 \%$. 
Tabela 6 - Efetivo dos rebanhos do município de Ouro Verde.

\begin{tabular}{lcccc}
\hline Tipo de rebanho & $\mathbf{2 0 0 0}$ & $\mathbf{2 0 0 5}$ & $\mathbf{2 0 1 0}$ & $\mathbf{2 0 1 3}$ \\
\cline { 2 - 5 } Bovino & Quantidade & Quantidade & Quantidade & Quantidade \\
Equino & 32.297 & 28.171 & 21.962 & 18.750 \\
Galináceas & 1.150 & 600 & 425 & 425 \\
Ovino & 13.200 & 12.050 & 5.400 & 5.150 \\
Suíno & 700 & 410 & 1.180 & 1.080 \\
Equino & 900 & 790 & 753 & 740 \\
\hline
\end{tabular}

Fonte: Pesquisa Pecuária Municipal do IBGE (2000 - 2013).

A partir da análise dos dados de fontes secundárias expostos neste trabalho, fica evidente que a redução da produção das lavouras temporárias e permanentes e do efetivo dos rebanhos possui estreita relação com a expansão dos canaviais.

\section{CONCLUSÃO}

A monocultura canavieira se expandiu em Ouro Verde a partir da década de 2000 e foi responsável por gerar uma série de impactos socioambientais significativos para a localidade pesquisada. Do ponto de vista social, a expansão da cana-de-açúcar aumenta a concentração de terra e de renda no campo, origina impactos sociais devido à sazonalidade do emprego e às migrações de trabalhadores que vêm para a região para trabalhar apenas no período da safra, desarticula as comunidades rurais e dificulta o desenvolvimento das atividades agropecuárias praticadas em pequena escala. No que diz respeito aos impactos ambientais, a expansão da monocultura canavieira provoca alteração na paisagem em virtude de sua homogeneização, poluição do solo, do ar e dos recursos hídricos em decorrência da utilização de agrotóxicos, morte de animais em decorrência das queimadas e a diminuição da biodiversidade.

Além dos impactos mencionados anteriormente, também constatamos que a expansão da cana-de-açúcar tem contribuído para a redução da produção das lavouras temporárias e permanentes e do efetivo dos rebanhos. Tal situação 
evidencia a fragilidade em que se encontra a produção de alimentos na localidade analisada nesse contexto expansionista.

A expansão da cana-de-açúcar proporcionou intensa reestruturação espacial, produtiva e econômica, bem como, gerou impactos socioambientais significativos no município analisado. Dessa forma, é necessário ter precaução com a expansão da monocultura canavieira, pois futuramente seus impactos poderão tornar-se ainda mais prejudiciais para o município de Ouro Verde.

\section{REFERÊNCIAS}

ALMEIDA, R. A. Territorialização do complexo eucalipto-celulose-papel em Mato Grosso do Sul. In: XXI Encontro Nacional de Geografia Agrária, 2012, Uberlândia. Anais XXI Encontro Nacional de Geografia Agrária. Uberlândia: UFU, 2012. p. 1-19. Disponível em: <http://www.lagea.ig.ufu.br/xx1enga/anais_enga_2012/eixos/1291_1.pdf>. Acesso em: 14 jun. 2014.

ANDRADE, M. C. Agricultura e capitalismo. São Paulo: LECH, 1979.

BEDUN, M. R. Os desafios da agricultura familiar camponesa frente à territorialização do agronegócio: perspectivas para o município de Tupi Paulista e seu entorno regional. Dissertação (Mestrado em Geografia). 2012. 138 f. Universidade Federal de Mato Grosso do Sul, Três Lagoas, 2012.

GIL, I. C. Nova Alta Paulista, 1930 - 2006: entre memórias e sonhos. Do desenvolvimento contido ao projeto político de desenvolvimento regional. 2007. $395 \mathrm{f}$. Tese (Doutorado em Geografia). Faculdade de Ciências e Tecnologia, Universidade Estadual Paulista, 2007.

GRAZIANO DA SILVA, J. A modernização dolorosa: estrutura agrária, fronteira agrícola e trabalhadores rurais no Brasil. Rio de Janeiro: Zahar, 1982.

IBGE. Instituto Brasileiro de Geografia e Estatística. Pesquisa Pecuária Municipal (2000 - 2012). Disponível em <http://www.sidra.ibge.gov.br>. Acesso em: 15 out. de 2014.

. Instituto Brasileiro de Geografia e Estatística. Produção Agrícola Municipal (2000 - 2012). Disponível em <http://www.sidra.ibge.gov.br> acessado em: 15 out. de 2014.

JOVIANO, C. V. M. Expropriação, luta e resistência: a questão camponesa no bairro "Maquininha", município de Dracena-SP. 2009. 172 f. Dissertação (Mestrado em Geografia). Universidade Federal da Grande Dourados, Dourados, 2009.

KUDLAVICZ, M. Dinâmica agrária e a territorialização do complexo celulose/papel na microrregião de Três Lagoas/MS. 2011. 177 f. Dissertação (Mestrado em Geografia). Universidade Federal de Mato Grosso do Sul, Três Lagoas, 2011.

LELIS, L. R. M.; HESPANHOL, R. A. M. Dinâmica agropecuária do município de Dracena - SP: da cafeicultura à cana-de-açúcar. Geografia em Questão, Marechal Cândido Rondon, v. 6, n. 2, p. 181198, 2013. Disponível em:

<http://e-revista.unioeste.br/index.php/geoemquestao/article/view/7805>. Acesso em: 30 jun. 2014.

MATOS, P. F.; PESSÔA, V. L. S. Territorialização da agricultura moderna na região da estrada de ferro (Goiás) e as modificações no espaço agrário. In: Encontro Nacional de Geografia Agrária, 2009, São Paulo. Anais XIX Encontro Nacional de Geografia Agrária. São Paulo: USP, 2009. p. 1-18. Disponível 
$<$ http://www.geografia.fflch.usp.br/inferior/laboratorios/agraria/Anais\%20XIXENGA/artigos/Matos_PF.p df>. Acesso em: 10 jun. 2014.

. A modernização da agricultura no Brasil e os novos usos do território. Revista Geo UERJ.

Ano 13, n. 22, v. 2. p. 290-322, 2011 . Disponível em: <http://www.epublicacoes.uerj.br/index.php/geouerj/article/view/2456>. Acesso em: 10 jul. 2014.

MARTINS, J. S. Capitalismo e tradicionalismo: estudos sobre as contradições da sociedade agrária no Brasil. São Paulo: Pioneira, 1975.

OLIVEIRA, A. U. A agricultura camponesa no Brasil. 2 ed. São Paulo: Contexto, 1996.

Barbárie e modernidade: o agronegócio e as transformações no campo. Reunião da Coordenação Nacional da Comissão Pastoral da Terra (CPT), Goiânia, out. 2003, p. 1-52.

SEGATTI, S. A expansão da agroindústria sucroalcooleira e a questão do desenvolvimento da Microrregião de Dracena - SP. 2009. 153 f. Dissertação (Mestrado em Geografia). Faculdade de Ciências e Tecnologia, Universidade Estadual Paulista, Presidente Prudente, 2009. 